\title{
Conceitos de familia e a tipologia familiar: aspectos teóricos para o trabalho da equipe de saúde bureal na estratégia de saiude da familia
}

\author{
Coneepts of family and family typology: theoretioal to the teamwork of oral \\ health in the family health strategy aspeets
}

\author{
Leonardo Carnut ${ }^{1}$ \\ Juliana Faquim ${ }^{2}$
}

\section{Resumo}

A busca pela integralidade com o foco na família tem sido um dos meios para a reorganização da Atenção Primária à Saúde no Brasil. A Política Nacional de Atenção Básica à Saúde do Ministério da Saúde, publicada em 2006, reafirma a família como sujeito do processo de cuidado e define o domicílio como o contexto social em que se constroem as relações intra e extrafamiliares, efetivando-se assim a luta pela sobrevivência e pelas condições de vida. Nesse sentido, a centralidade na família é objeto dessa e de várias outras políticas sociais e ações públicas em função dos interesses do Estado, da sociedade civil e de organismos internacionais. A inserção da saúde bucal na Estratégia de Saúde da Família trouxe um novo cenário de atuação e se tornou um espaço social favorável para as ações de promoção, prevenção e assistência individual ofertadas na Atenção Primária à Saúde pela Equipe de Saúde Bucal. O objetivo do presente artigo é trazer os aspectos fundamentais pautados na literatura sobre o conhecimento necessário que a Equipe de Saúde Bucal (EqSB) deve ter sobre família assim como suas peculiaridades no trabalho cotidiano da estratégia de saúde da família.

\section{Abstraet}

According to reorganization of primary health care in Brazil, looking for comprehensive care based on family has been one of the means of Family Health Strategy. The National Primary Care Policy at the Ministry of Health, published in 2006, reaffirms the family as the subject of the care and defines domicile as the social context in which they build intra-and extra-familial relationships. In this sense, the "family centrality" is the object of this and several other social policies and public actions in the interests of the State, civil society and international organizations. The integration of oral health in the Family Health Strategy has brought a new scenario of action and became a supportive social space for promotion, prevention and individual assistance offered by Oral Health Teams. The purpose of this article is to bring fundamental aspects guided by the literature on the knowledge that the Oral Health Team (OHT) should have on their family as well as peculiarities in the daily work of family health strategy.

Deseritores: SUS, familia, programa saúde da familia, saúde bucal

Keywords: Unified Health System, Family, Family Health Program, Oral Health

\footnotetext{
1 Professor do eurso de Odontologia da Universidade de Pernambueo Campus Areoverde e de Saúde Coletiva Campus Reeife.

2 Professora do Curso Téenico em Saúde Bucal da Eseola Téenica de Saúde da Universidade Federal de Uberlândia.

Para correspondência:

Leonardo Carnut

E-mail:leonardo.carnut@gmail.com
} 
Introducã̃o

A reorganização da Atenção Primária à Saúde (APS) no Brasil adquiriu uma nova forma de conceber o cuidado da população em busca de uma integralidade do ser humano desde a instituição do Sistema Único de Saúde (SUS). Uma parte da busca por essa integralidade é realizada transferindo-se o foco do cuidado do "indivíduo" para a "família" como lócus de ação das intervenções. Mas para os mais "desavisados" parece que apenas essa questão é o que justifica que a categoria família seja o centro do cuidado em saúde.

Na realidade a centralidade da família não é um aspecto apenas do setor saúde. Várias outras políticas sociais no Brasil (como também em outros países) adotam a família como objeto de ações públicas. Podemos citar o programa "Bolsafamília" (na assistência social), o "Programa Universidade para todos - PROUNI" (na educação), o programa "Minha casa, minha vida" (na habitação) e isso só para observarmos alguns dos programas sociais mais conhecidos.

Na saúde, como dito anteriormente, isso não é diferente! A família goza de um lugar central na política de saúde e isso é materializado por meio da "Estratégia de Saúde da Família". Você já parou para pensar o quanto você sabe sobre "famílias"? É razoável que alguém trabalhe no "saúde da família", sem entender o que são "famílias"? Como essas se organizam? Qual sua importância social?

Diante destes questionamentos, parece que a família tem algo importante a ser entendido e estudado por ser utilizada como base operacional de tantas políticas sociais. De fato, não é à toa que a família é o "centro das atenções", e é sobre isso que vamos nos debruçar.

Neste artigo, comentaremos os aspectos fundamentais sobre o conhecimento necessário que a Equipe de Saúde Bucal deve ter sobre família assim como suas peculiaridades no trabalho cotidiano da Estratégia de Saúde da Família. Além disso, entendendo a Equipe de Saúde da Família como uma equipe completa que compõem todos os membros (incluindo aí o Auxiliar e o Técnico em Saúde Bucal), vamos sempre nos referir à equipe como um todo, em que o conhecimento aqui dissertado deve servir para o compartilhamento entre seus membros.

\section{Familia: conceito}

O conceito de família se modifica conforme o tipo de sociedade, o tempo e a sua estrutura social, na medida em que sofre as influências dos acontecimentos sociais ${ }^{1}$. No entanto, tomaremos como base dois conceitos de família que são de grande valia, devido à facilidade de compreensão. Duas ciências servirão de suporte para isso: a psicologia e a sociologia.

Para a psicologia 2,3 família é:

Um grupo de pessoas, vivendo em uma estrutura hierarquizada, que convive com uma proposta de uma ligação afetiva duradoura, incluindo uma relação de cuidado entre adultos e deles para crianças e idosos que aparecem no contexto. Pode-se também entender como uma associação de pessoas que escolhe conviver por razões afetivas e assume um compromisso de cuidado mútuo e, se houver, com crianças, adolescentes e adultos.

Nessa perspectiva psicológica, pode-se entender a família como um grupo de coesa relação interpessoal, ocasionada de forma impositiva ou não e que se observa, mesmo que minimamente, alguma relação de hierarquia e cuidado entre seus membros. Já para sociologia família é:

Um grupo que apresenta organizações estruturadas para preencher as contingências básicas da vida biológica e social. Trata-se de uma unidade social básica, ou seja, o grupamento humano mais simples que existe, por isso a família é a instituição básica da sociedade ${ }^{4}$.

Apoiando-se na visão sociológica, percebe-se que a família ganha um caráter de "unidade primária". Pode-se dizer então que sem a família, seríamos um aglomerado de sujeitos particulares sem ligação interpessoal com os demais membros da mesma espécie e que não haveria o mínimo de coletividade entre os seres humanos. Se a espécie humana existe hoje, em grande parte isso é fato devido ao embrião da reciprocidade e do altruísmo mútuo que emergiu ao se organizar esses primeiros grupamentos humanos chamados de família.

Alguns conceitos, como os de matrimônio e parentesco, estão muito associados à idéia que as pessoas têm sobre o âmbito familiar, entretanto é 
um equívoco quando esses dois conceitos são confundidos com o termo "família". Matrimônio significa a união ou vínculo estabelecido entre duas pessoas, mediante o reconhecimento governamental, religioso ou social e que pressupõe uma relação interpessoal de intimidade embora possa ser visto por muitos como apenas um contrato. Parentesco está relacionada à cosanguinidade existente entre gerações, fruto ou não de um processo matrimonial e de constituição familiar.

É normal as pessoas no dia-a-dia confundirem esses termos, achando que se tratam da mesma coisa. Um dia, em determinado período histórico, nas sociedades ocidentais (em especial, as eurocêntricas) esses termos se confundiam, pois para haver famílias, era necessário um matrimônio e admitia-se que os membros frutos desse matrimônio (os parentes) eram a "família" propriamente constituída. Contudo, hoje em dia, famílias podem ser constituídas sem haver o matrimônio e muito menos ainda gerarem parentesco entre as partes.

\section{Tipologja familiar ou composieñes familiares}

A classificação mais utilizada pelos estudos de psicologia e sociologia é a Classificação de Kaslow $^{5}$ de composição familiar, que consiste no arranjo dos membros que compõem esta família. Segundo o autor, a família pode ser classificada em:

a) família nuclear, incluindo duas gerações com filhos biológicos;

Dentre todas as configurações, a família nuclear é a mais observada e aceita socialmente na cultura ocidental ${ }^{6}$. Nem sempre essa configuração foi hegemônica na história brasileira ${ }^{7}$, como será visto mais adiante.

Família nuclear é aquela composta de um homem e uma mulher que coabitam e mantêm um relacionamento sexual socialmente aprovado, tendo pelo menos um filho ${ }^{8}$. De maneira mais estrita, Popenoe 9 se refere ao termo "família nuclear tradicional" se tratando daquela onde a esposa trabalha em casa sem ser remunerada, enquanto o marido trabalha fora de casa por um salário. Esse arranjo torna o homem "o provedor primário e autoridade máxima". Atualmente, quando as pessoas se referem ao declínio da família, estão se referindo a configuração nuclear tradicional, em detrimento do surgimento de formas alternativas (Quadro 1).

\begin{tabular}{|c|c|}
\hline $\begin{array}{ll}\text { Família } & \text { Nuclear } \\
\text { Tradicional } & \\
\end{array}$ & Novas Alternativas \\
\hline União legal & Solteiros, união consensual \\
\hline Com filhos & Voluntariamente sem filhos \\
\hline Pai e mãe & $\begin{array}{l}\text { Pai ou mãe (nunca casados ou } \\
\text { separados) }\end{array}$ \\
\hline Permanente & Divórcio, reconstituição \\
\hline $\begin{array}{l}\text { Homem como } \\
\text { provedor primário e } \\
\text { autoridade única }\end{array}$ & $\begin{array}{l}\text { Casamento } \\
\text { (incluindo carreira de ambos os } \\
\text { cônjuges e casais que residem } \\
\text { em lugares diferentes) }\end{array}$ \\
\hline Exclusividade sexual & $\begin{array}{l}\text { Relações } \\
\text { (incluindo cxtramaritais } \\
\text { sexualmente abertos, prática de } \\
\text { troca de casais e amizades } \\
\text { íntimas) }\end{array}$ \\
\hline Heterossexualidade & $\begin{array}{l}\text { Relações íntimas entre pessoas } \\
\text { do mesmo sexo }\end{array}$ \\
\hline $\begin{array}{l}\text { Domicílio com dois } \\
\text { adultos }\end{array}$ & $\begin{array}{l}\text { Domicílio com mais de dois } \\
\text { adultos (incluindo múltiplos } \\
\text { cônjuges, habitação } \\
\text { famílias } \\
\text { multigeracionais) }\end{array}$ \\
\hline
\end{tabular}

Quadro 1. Diferenças entre a tipologia nuclear tradicional e os novos tipos alternativos de família na contemporaneidade.

Fonte: Adaptado por Macklin ${ }^{10}$

b) famílias extensas, incluindo três ou quatro gerações;

As famílias extensas são compostas pelo núcleo familiar e agregados que coabitam a mesma unidade doméstica. De certo modo, a família extensa foi substituída pela família nuclear, especialmente, nos grandes centros urbanos. Além disso, difundiram-se novos arranjos familiares desvinculados da união legal11.

c) famílias adotivas, que podem ser bi-raciais ou multiraciais;

A possibilidade da adoção disposta no Código Civil Brasileiro, faz com que a composição da família adotiva se tornasse realidade. Esta é composta por um homem e mulher cujo filho não apresenta laços de consangüinidade ${ }^{12}$.

d) casais;

A família dita "casal" é aquela em que o homem e mulher se enlaçam via matrimônio, mas 
não concebem nem adotam filhos.

e) famílias monoparentais, chefiadas por pai (masculina) ou mãe (feminina);

Os lares monoparentais são aqueles que vivem com um único progenitor, com os filhos que não são ainda adultos"13. A expressão "famílias monoparentais" foi utilizada na França, desde a metade dos anos 70, para designar as unidades domésticas em que as pessoas vivem sem cônjuge, com um ou vários filhos com menos de 25 anos e solteiros $^{14}$. A transformação das formas de vida conjugal manifesta-se pelo aumento de um tipo especial de família: a monoparental, predominantemente feminina. Resultante da taxa de divórcio e recasamentos, com a conseqüente recomposição do casal, isso permitiu numa desinstitucionalização do casamento ${ }^{15}$.

f) casais homoafetivos (homoparentais), com ou sem crianças;

Apesar de ser um fenômeno antigo, a homoparentalidade sempre existiu, pois sempre existiram gays e lésbicas com filhos. A novidade está na dissociação entre sexualidade e procriação, como também nas várias possibilidades que os homossexuais têm de viver a experiência da parentalidade. Essas famílias são constituídas por pessoas do mesmo sexo que têm filhos via três caminhos: (a) reconstituição - um dos parceiros traz para a relação homossexual os filhos do casamento anterior; (b) a adoção - legalizada ou não; (c) a co-parentalidade - em que um dos membros do casal gera uma criança com uma pessoa que oferece parceria biológica e o filho passa a fazer parte do núcleo parental do pai ou mãe homossexual ${ }^{16}$.

g) famílias reconstituídas, após divórcio;

A flexibilidade na legislação civil ainda permitiu uma nova configuração: as famílias reconstituídas. O recasamento, fenômeno cada vez mais comum atualmente, surgiu como uma possibilidade de reconquistar vínculos essenciais de intimidade, companheirismo e afeto. Estas uniões não só exaltaram as maneiras de estar ou ser casado, como ainda provocam o aparecimento de novos arranjos familiares ${ }^{17}$.

h) várias pessoas vivendo juntas, sem laços legais, mas com forte compromisso mútuo.

Como se pode perceber, há uma clara transformação na instituição familiar, pois o que se vê é o surgimento de novos modos de ser entre homens e mulheres e seus filhos, partilhados por muitos casais contemporâneos e que terminarão por constituir novas regras ${ }^{15}$.

\section{Importância social da familia}

A importância social da família se dá por esta ser o principal agente de socialização e reproduzir padrões culturais no indivíduo. Ela "inculca" modos de pensar e atuar que se transformam em hábitos ${ }^{18}$. A família é o primeiro sujeito que referencia e totaliza a proteção e a socialização dos indivíduos.

Esta, por sua vez, vem sendo apontada como elemento-chave não só para a "sobrevivência" dos indivíduos, mas também para a proteção e a socialização, transmissão do capital cultural, do capital econômico e da propriedade do grupo, bem como para ampliar as relações de gênero e de solidariedade entre as gerações ${ }^{19}$. Na família, destacam-se três momentos importantes de socialização de seus membros.

\section{a) Identificação do núcleo social inicial:}

Identificação dos pais como primeiro núcleo social da criança, pois esses apresentam uma grande influência no seu processo de desenvolvimento cognitivo, social e psicológico. É a relação com os pais que constitui a base referencial de todas as outras, por serem responsáveis em transmitir as primeiras informações e interpretações sobre o mundo ${ }^{20}$.

\section{b) Socialização primária:}

Nessa socialização, a família é o agente mais importante no processo de internalização e aprendizagem, pois fornece o marco para a definição e conservação das diferenças humanas, dando forma aos papéis sociais básicos ${ }^{21}$. $\mathrm{Na}$ primeira socialização é como o processo pelo qual uma ordem social e cultural é "mediatizada" por outros significados, e, através da identificação destes, sucede-se a interiorização do mundo social no qual se nasce.

c) Socialização secundária: 
Ocorre quando o sujeito entra em contato com grupos extrafamiliares, sem desmerecer a força significativa da sedimentação das normas e valores que foram apreendidos através da socialização primária ${ }^{22}$.

Nesse período outras relações sociais colaboram para o desenvolvimento de crianças e adolescentes, em especial, as relações vividas na escola e nos grupos de colegas (já na adolescência).

Quando a família deixa de cumprir suas funções básicas juntos aos seus membros, acaba gerando custos sociais e financeiros adicionais, na medida em que iniciativas públicas e privadas compensatórias, que nem sempre são eficazes, tornam-se necessárias para cobrir as demandas dali originadas ${ }^{23}$. Não obstante a formação de profissionais deve estar atenta à consideração de interdisciplinaridade da área de estudos da família e todas as dimensões da mesma devem ser consideradas, desde as relações interpessoais até sua inserção na sociedade mais ampla ${ }^{3}$.

\section{Familia e Saúde}

Há evidências científicas que as famílias determinam a saúde dos seus membros por meio de vários processos (por exemplo, os conflitos, suporte). Há também evidências de que a saúde dos membros da família constroem tipos de funcionamento familiar (por exemplo, via "enfrentamento dos problemas") e bem-estar dos seus membros (por exemplo, em situação de cuidado com o outro ${ }^{24}$ ). Podemos, portanto, dizer que o binômio família-saúde é uma via de "mão dupla".

De uma forma geral, as relações familiares entre dois membros da família (chamadas de diádicas) como por exemplo, pai-filho, mãe-filho ou a própria composição da família são responsáveis ou pela manutenção da saúde da criança/adolescente ou pelo adoecimento da criança/adolescente saudável.

Isso acontece por que essas relações são fruto da hierarquia (etária) presente ${ }^{25}$ entre seus indivíduos, deste modo, como já vimos, os adultos são "referências" emocionais e culturais para as crianças/adolescentes e estes últimos se socializam reproduzindo o padrão de comportamento de seu núcleo social inicial.
Nesses casos a determinação na saúde das crianças e adolescentes é dada de forma verticalizada "de cima para baixo" (ou seja, dos mais velhos para os mais novos). Nesses casos a característica da família geralmente não é o suficiente para a dissolução familiar. Por serem problemas diádicos, restringem-se a um "subgrupo" da família, e tende a ter um caráter muito restrito à esfera privada da mesma. Por causa disso, as características da família se incutem e se perpetuam ao longo do tempo a geração seguinte de uma forma muito discreta.

O contrário também acontece. A criança/adolescente doente constrói na vida familiar dos indivíduos um processo social verticalizado "de baixo para cima" e horizontalizada (atingindo irmãos e outros membros da mesma geração) devido à questão do investimento parental necessário para sobrevivência do infante. Neste caso a âmbito familiar fica comprometido e nos casos mais graves pode até se desfazer, e a família ficará vulnerável e muito dependente de uma rede social de apoio que a ajude a "funcionar adequadamente". Por isso se diz que, nesses casos, há uma "abertura" da família à esfera pública mais facilitada como também pode-se perceber menos tabus e preconceitos na discussão desses problemas ${ }^{26}$. Resumindo podemos dizer, de forma bem simplificada, que temos dois casos principais:

a) características da família $\rightarrow$ determina a saúde dos indivíduos (crianças/adolescentes)

Exemplos:

(1) A escolaridade dos pais: Muitos estudos em diversas áreas já confirmam a influência da baixa escolaridade dos pais (em especial a da mãe) como fator que "gera" doença nas crianças e adolescentes. Isso parece meio sem sentido em uma análise despretensiosa, contudo há uma lógica explicativa razoável para este fenômeno. Quanto menos anos de estudo os pais de determinada criança tem, mais chance das mesmas se exporem a riscos e não passarem por chancelas dos pais. Em saúde materno-infantil trata-se, por exemplo, do caso clássico da morte neonatal por falta de cuidado das mães de baixo nível de escolaridade. Não significa que elas não gostem de seus filhos, mas é que elas não têm capacidade cognitiva para reconhecer perigos a que os bebês se expõem.

(2) O papel da mulher na família 
moderna: A mulher (esposa) é um membro familiar que acumula um conjunto de papéis muito grande na sociedade moderna. Elas têm que ser cuidadoras do lar, serem boas esposas, trabalharem fora, se qualificarem por meio do estudo, além de serem mães. Fora isso a sociedade em que vivemos, culturalmente expõem a mulher como objeto de desejo sexual, coisificando-a, e àquelas que não se enquadram no padrão de beleza tendem a ser marginalizadas. Todo esse conflito de papéis gera estresse nas mulheres que fatalmente interfere na sua saúde física. Os filhos consequentemente recebem o estresse materno em forma de negligência, irritação ou até mesmo superprotecionismo. Daí a necessidade de divisão de tarefas e funções entre os pais na criação dos filhos para evitar a superexploração de um dos pais, que pela cultura local tende a ser a mulher.

b) evento ou doença que acomete um membro da família $\rightarrow$ constrói um novo processo de funcionamento familiar e pode reconfigurar a composição familiar

\section{Exemplos:}

(1) O nascimento: do ponto de vista da longitudinalidade, podemos dizer que a primeira influencia se apresenta da criança em relação ao adulto é na hora do nascimento. Principalmente quando não é planejado ou acomete casais adolescentes. A precocidade em assumir a responsabilidade da parentalidade gera estresse e se reflete no corpo através do cansaço físico e emocional. Ao se chegar na vida adulta os jovens pais geralmente se sentem mais esgotados, envelhecem mais cedo e apresentam uma pior percepção de sua saúde ${ }^{27}$.

(2) As doenças crônicas: Alguns autores ${ }^{28}$ colocam como a criança e sua situação de fragilidade constrói um novo funcionamento familiar. As doenças crônicas pediátricas (leucemia, diabetes, hipertensão, obesidade, doenças psiquiátricas etc.) são um fator de risco entre os membros da família, podendo gerar um desregulação da mesma. Uma criança portadora de doença crônica na família influencia negativamente na relação com irmão, pais e promovem muitas vezes conflito de papéis e discórdia conjugal.

Esses casos acima são os mais corriqueiros no dia-a-dia das famílias no cenário da hipermodernidade que vivemos hoje. Eles acontecem independentes de classe social e afetam a saúde dos seus membros através de formas muito subliminares que às vezes não nos damos conta. Quando um pai ou uma mãe transfere o estresse acumulado diariamente em seus filhos, muitos efeitos podem acontecer que reflitam na sua saúde. Desde a compensação por meio de doces e guloseimas (que geram obesidade, cárie etc) até o uso de drogas. Por isso não devemos menosprezar esses episódios, pois muitas vezes eles podem ser a causa de uma doença muito grave que venha a se instalar.

\section{As "Familias" o seus principais desafios no trabalho cotidiano na Estratégia de Saúde da Familia}

Apesar dos eventos acima colocados serem bem gerais e acometerem geralmente quaisquer famílias, existem casos que são relativamente comuns em áreas de saúde da família. As equipes de saúde devem se preparar para entender como essas famílias se organizam, o que "passam na cabeça" de seus membros, para podermos melhor ajudá-los a lidarem com seus problemas e não geraram doenças desnecessariamente.

a) As monoparentais femininas e a dependência dos "outros";

Como já foi exposto anteriormente, a mulher na sociedade moderna geralmente trabalha fora para complementar a renda doméstica. Entretanto o problema se agrava bastante quando a mulher é, como popularmente chamam "mãe-solteira". Do ponto de vista técnico, podemos dizer que a família constituída de uma mãe com um filho ou mais (como vimos nas secções anteriores desse artigo) chama-se monoparental feminina. Essa família tem aumentado bastante devido a possibilidade de divórcio, à desromantização do casamento, e ao cultivo do individualismo.

Gerar o sustento e cuidar de crianças pequenas é uma situação praticamente impossível para essas famílias a não ser quando alguém as ajuda. Geralmente os vizinhos, ou parentes que moram perto ajudam na criação dos infantes. Entretanto, a socialização primária dessas crianças, que antes seria monopólio da mãe, será do "cuidador" que com elas estiverem. Por isso o trabalho da equipe de saúde, nesses casos, deve ser focado no "cuidador" do que propriamente na mãe. A equipe de saúde deve intensificar o cuidado a essas famílias com o objetivo de monitorar a saúde dessas crianças que fatalmente tendem a 
adoecerem mais.

b) Emancipação precoce de casais adolescentes;

É muito comum (principalmente em nas periferias dos grandes centros urbanos) os jovens casarem cedo. Muitas explicações podem surgir para esse fenômeno. Necessidade de sair de casa devida à sensação de intolerância vinda pais, ganho de status social por passarem a ser "donos de casa", ou "pais de família", ou ainda a mera falta de perspectiva para o futuro são os principais motivos que fazem com que jovens se casem precocemente. $\mathrm{O}$ fato é que, pais adolescentes não estão maduros suficientemente para cuidarem de sua prole. Muitas vezes não estão nem inseridos no mercado de trabalho. Quando situações desse tipo ocorrem, ou os avós se responsabilizam pelas crianças, ou nas situações mais extremas, formas de trabalho que não são socialmente aceitas (como a prostituição, tráfico de drogas/bebidas etc.) são a saída para gerar renda. $\mathrm{O}$ trabalho das equipes de saúde com os adolescentes é fundamental para que esses casos não aconteçam. E se porventura acontecerem, a equipe de saúde deve se responsabilizar de forma mais intensiva nesses casos pois não apenas as crianças sofrem com isso como também os pais adolescentes

c) "Quando o núcleo não são os pais": a exploração financeira de avós e deficientes físicos;

Pela situação da previdência social e por programas de assistência social, os idosos e os deficientes físicos têm o direito adquirido de receberem benefícios financeiros do Estado. Contudo, na atualidade, o desemprego e/ou a baixa qualificação dos demais membros de família pobres impedem que estes alcancem postos de trabalho formais e consequentemente, não consigam gerar renda. Quando isso acontece, a saída de muitas famílias (em especial as extensas) é viver da exploração da renda oriunda de um beneficiário de programas sociais. As equipes de saúde, ao reconhecerem estes casos, devem ficar atentas pois casos de violência (principalmente psicológica) aos idosos e deficientes são frequentes nessas situações.

d) $\mathrm{O}$ descuido pela quantidade: as crianças nas famílias extensas;
Ao contrário do que todos pensam, a literatura científica coloca que algumas doenças se instalam mais frequentemente em crianças mais novas em família extensas devido à grande quantidade de filhos que um casal possa vir a ter. Mesmo os "agregados" e outras pessoas que ajudam no cuidado com as crianças, os "caçulas" tendem a serem marginalizados na atenção dispensada pelos pais e familiares, e essas crianças tendem a se expor a riscos com maior frequência. Portanto, as equipes de saúde ao trabalhar com famílias extensas devem enfatizar sua atenção aos filhos mais novos que, geralmente, acumulam mais doenças ou estão expostos a mais riscos que os demais.

e) Abandono de pacientes portadores de transtornos mentais;

Os pacientes que são portadores de transtornos mentais, infelizmente já são cotidianamente estigmatizados na sociedade atual. Com isso, seus familiares geralmente tendem a seguir o mesmo padrão de comportamento de marginalização (mesmo quando esses estão sob seus cuidados).

Em famílias pobres, isso é muito mais grave pois há uma questão financeira envolvida, que reforça a visão do portador de transtorno mental como mais um "gasto" não-desejado. Nessa perspectiva, o abandono desses indivíduos é o principal problema que os acometem e, juntamente com isso, vem toda sorte de doenças que esses podem adquirir. As equipes de saúde da família têm por obrigação encaminhar esses casos para acompanhamento através dos serviços de saúde mental e assistência social de forma conjunta.

\section{f) Perpetuação dos adultos na casa dos pais;}

O convívio entre pais e filhos, mudou significativamente nos últimos anos e, em muitos casos, tem sido possível identificar um fenômeno popularmente conhecido por "geração canguru".

Esse fenômeno se caracteriza por um prolongamento da convivência familiar, na qual jovens adultos que já concluíram a graduação universitária possuem condições de independência financeira e de terem sua própria moradia, mas continuam morando na casa dos pais. Apesar de ser uma minoria dos casos, mas é um fenômeno que vem crescendo e tende a ser a 
nova configuração de família nas próximas gerações.

g) "A diferença que incomoda": os casais homoafetivos;

Recentemente, o Supremo Tribunal Federal (STF) decidiu por unanimidade à favor da união estável de homossexuais, o que garante aos gays o direito de adoção, herança, plano de saúde compartilhado e pensão. Tudo mostra que a sociedade brasileira, felizmente caminha em direção ao respeito à diversidade sexual. Ao contrário do que muitos pensam, a homossexualidade não se trata de uma escolha, portanto o respeito a homo afetividade entres os pares é fundamental na constituição de uma sociedade saudável.

Infelizmente, as crianças filhas de pais homossexuais ainda sofrem muito preconceito e são rechaçadas do convívio social pelos colegas (e muitas vezes pelos pais dos colegas dessas crianças). Isso pode gerar sequelas psicológicas sérias que podem gerar, em casos mais extremos até a morte dessas crianças via violência física. As equipes de saúde devem estar atentas a esses casos e orientar as famílias em encontros de grupo trabalhando o respeito às diferenças.

h) "Quando as famílias nucleares silenciam": a violência intrafamiliar

A violência intrafamiliar é toda ação ou omissão que prejudique o bem-estar, a integridade física, psicológica ou a liberdade e o direito ao pleno desenvolvimento de outro membro da família. Pode ser cometida dentro ou fora de casa por algum membro da família, incluindo pessoas que passam a assumir função parental, ainda que sem laços de consanguinidade, e em relação de poder à outra. Esse tipo de problema familiar é sem dúvida o mais frequente e o mais difícil de identificar. Seja pelo caráter privado que a família se reserva, seja pelo não reconhecimento do que de fato é violência!

Todos dos tipos de injúria físicas (como tapas, socos, murros, queimaduras, mordeduras) até constrangimentos em público (como tirar a força de casa, arrancar a roupa, ou abandonar em lugares desconhecidos) são consideradas tipos de violência intrafamiliar (incluindo também a violência de cunho sexual). Infelizmente, ainda hoje, as pessoas submetidas à violência intrafamiliar, principalmente as mulheres $\mathrm{e}$ crianças, muitas vezes culpam-se de ser responsáveis pelos atos violentos, percepção que é reforçada pelas atitudes da sociedade.

Por isso, é responsabilidade do profissional de saúde estar atento quanto à possibilidade de um membro da família estar praticando ou sendo vítima de violência, mesmo que não haja, à primeira vista, indicações para suspeitas. Por meio de observações, visitas domiciliares, perguntas indiretas ou diretas dirigidas a alguns membros da família, situações insuspeitas podem ser reveladas se houver um cuidado e uma escuta voltada para estas questões. Mesmo que a família tente ocultar tais situações, a aproximação por parte do profissional poderá facilitar a abertura a um diálogo futuro, criando novos espaços de ajuda $^{29}$.

\section{Consideraţões finais}

A partir do que foi exposto, considera-se importante que a equipe de saúde bucal compreenda a "família" como objeto de trabalho e espaço social favorável para as ações de promoção, prevenção e assistência individual ofertadas na Atenção Primária à Saúde. Assim, é fundamental que a equipe desconstrua a visão tradicional e "romântica" de família e entenda que a família pode ser, por um lado, um espaço de apoio à sobrevivência e proteção integral à saúde dos filhos e demais membros e por outro pode ser fonte de relações que gerem riscos à saúde e provoquem doenças.

Como espaço de vivência das emoções dos afetos extremos como o nascimento e a morte, espaço de conflito e também de reconciliação em que as pessoas aprendem a se relacionar, a família justifica sua complexidade e demonstra a necessidade de dedicação intelectual sobre o tema. Local no qual o crescimento, o desenvolvimento e o bem-estar dos seus indivíduos estão em jogo, a(s) "família(s)", são, sem dúvida, um dos principais desafios no trabalho na Estratégia de Saúde da Família, especialmente no que tange a educação informal e apoio à educação formal (principal determinante social do processo saúde-doença de possível intervenção pela equipe). 
Cotidianamente, a equipe de saúde bucal se depara com as diversas situações familiares elencada nesse artigo. Cabe aos membros da equipe (em especial do Técnico e do Auxiliar de Saúde Bucal) agir sobre essas realidades, mas não de forma desqualificada, mas sim detendo as habilidades e competências para transpor esses desafios e promover, mesmo em meios adversos, o cuidado e atenção à saúde bucal na vida das pessoas.

\section{Referêneias}

1. Vital MS. A família e sua projeção frente aos direitos humanos internacionais. Artigo apresentado no curso de Direitos Humanos Internacionais - JEP. Projeto de Jurisprudência da Igualdade. Faculdade de Direito. Universidade Federal do Mato Grosso. 2002.

2. Gomes HSR. Um estudo sobre o significado de família. Tese de Doutorado. PUC-SP, 1988.

3. Szymanski H. Viver em família como experiência de cuidado mútuo: desafios de um mundo em mudança. Revista Quadrimestral de Serviço Social. 2002; 71:9-25.

4. Durkheim E. As regras do método sociológico. 18581917. São Paulo: Editora Martins Fontes; 2007.

5. Kaslow FW. Families and Family Psychology at the Millenium.American Psychologist . 2002, 56(1):37-46.

6. Amazonas MCLAA, Damasceno RP,Terto LMS.; Silva RR. Arranjos Familiares de Crianças das Camadas Populares. Psicologia em Estudo. 2003; 10:11-20.

7. Freyre G. Sobrados e Mucambos: Decadência do Patriarcado Rural e Desenvolvimento do Urbano. Rio de Janeiro: José Olympio; 1985.

8. Brym RJ, Lie J, Hamlin CL, Mutzenberg R, Soares EV, Maior HPS. Sociologia - Sua bússola para um novo mundo. São Paulo: Cengage Learning, 2008. $585 p$.

9. Popenoe D. Disturbing the Nest: Family Change and Decline in Modern Societies. Nova York. 1988.

10. Macklin ED. Nontradicional family forms: A decade of research. Journal of Marriage and the Family 1980; 4:902-922.

11. Minuchin S. Famílias: Funcionamento e tratamento. Porto Alegre: Editora Artes Médicas, 1990.

12. Fonseca C. Mãe é uma só? Reflexões em torno de alguns casos brasileiros. Psicologia USP; 2002 13(2)49-68.

13. 13.Vitale MAF. Famílias Monoparentais: Indagações. Revista Quadrimestral de Serviço Social 2002; 71:4562.

14. Lefaucher N. Les famillesdites monoparentales. In: Sinly, F. La Famille: les etats de savoir . Paris, Éditions la découverte, 1997.

15. Boutin G, Durning, P. Les interventions auprès de parents. Toulouse, Privat, 1994.

16. Passos MC. Entre dois pais ou duas mães. In: Pinto, G.C. Uma Questão de Gênero - Sexos: a trama da vida. São Paulo: Editora Duetto Editorial, 2008 p.6067.
17. Cerveny C,Berthoud C. Família e Ciclo Vital - Nossa realidade em pesquisa. São Paulo: Editora Casa do Psicólogo. 1997

18. Lasch C. Refúgio num mundo sem coração - A família: santuário ou instituição sitiada? Rio de Janeiro: Paz e terra, 1991.

19. Carvalho IMM, Almeida, PH. Família e proteção social. São Paulo em perspectiva 2, 2003.

20. Salvador APV, Weber LND. Práticas educativas parentais: um estudo comparativo da interação familiar de dois adolescentes distintos. Interação em Psicologia. 2005; 9(2):341-353.

21. Takashima GMK. O desafio da política de atendimento à família: Dar vida às leis - uma questão de postura. In: KALOUSTIAN, S.M. Família Brasileira - A base de tudo. 8a. Edição. São Paulo: Cortez, Brasília, DF, UNICEF, 2008.

22. Berger PL, Luckmann, TA . Construção social da realidade: Tratado de Sociologia do Conhecimento. Petrópolis: Editora Vozes, 1985.

23. Ferrari M, Kaloustian SM. Introdução. In: Kaloustian, SM. Família Brasileira - A base de tudo. 8a. Edição. São Paulo: Cortez, Brasília, DF, UNICEF, 2008.

24. Proulx CM, Snyder LA. Families and Health: An Empirical Resource Guide for Researchers and Practitioners. Family Relations 2009; 58:489-504.

25. Eichelsheim VI, Dekovic M, Buist KL, Cook WL. The Social Relations Model in Family Studies: A Systematic Review. Journal of Marriage and Family 2009; 71:1052-1069.

26. Spiess CK, Dunkelberg A. The Impact of Child and Maternal Health Indicators on Female Labor Force Participation after Childbirth: Evidence for Germany. J Comp Fam Stud 2009; 40(1):119-138.

27. Taylor JL. Midlife Impacts of Adolescent Parenthood.Journal of Family Issues 2009; 30(4):484510.

28. Cohen MS. Families coping with childhood chronic illness: A research review. Families, Systems and Health 1999; 17:149-164.

29. Brasil. Ministério da Saúde. Secretaria de Políticas de Saúde.Violência intrafamiliar: orientações para prática em serviço / Secretaria de Políticas de Saúde. - Brasília: Ministério da Saúde, 2001. 96 p.: il. - (Série Cadernos de Atenção Básica; n. 8) - (Série A. Normas e Manuais Técnicos; n. 131). 